\title{
The HBV.IANIGLA Hydrological Model
}

by Ezequiel Toum, Mariano H. Masiokas, Ricardo Villalba, Pierre Pitte and Lucas Ruiz

\begin{abstract}
Over the past 40 years, the HBV (Hydrologiska Byråns Vattenbalansavdelning) hydrological model has been one of the most used worldwide due to its robustness, simplicity, and reliable results. Despite these advantages, the available versions impose some limitations for research studies in mountain watersheds dominated by ice-snow melt runoff (i.e., no glacier module, a limited number of elevation bands, among other constraints). Here we present HBV.IANIGLA, a tool for hydroclimatic studies in regions with steep topography and/or cryospheric processes which provides a modular and extended implementation of the HBV model as an R package. To our knowledge, this is the first modular version of the original HBV model. This feature can be very useful for teaching hydrological modeling, as it offers the possibility to build a customized, open-source model that can be adjusted to different requirements of students and users.
\end{abstract}

\section{Introduction}

Hydrological modeling is widely used by engineers, meteorologists, geographers, geologists, and researchers interested in knowing the runoff of rivers in the coming days or the variations of the snowpack under certain temperature or precipitation changes, among many other hydrological processes.

The Swedish Meteorological and Hydrological Institute (SMHI) ran the first successful simulation of the HBV model in 1972. It was developed to forecast river runoff for hydropower generation in Sweden (Bergström and Lindström, 2015). Up to now, many versions have been developed: HBV-ETH (Switzerland - Braun and Renner (1992) ), HBV-Light (Switzerland - Seibert and Vis (2012)), HBV-D (Germany - Krysanova et al. (1999) ), HBV-CE (Canada - Stahl et al. (2008) ), TUWmodel (Austria Viglione and Parajka (2016) ), among others. Despite all these free versions, none of them allows the users to build their own model using a self-defined combination of modules.

Buytaert et al. (2008) identified some prerequisites for hydrological model development: (1) accessibility in order to reproduce experimental results; (2) modularity as a key element for the development of new 'ad-hoc' models to evaluate several aspects of the hydrological cycle and to propose improvements; (3) portability, so the model can run in many operating systems; and (4) open-source code as a fundamental scientific requirement that allows users to revise, correct, and suggest code improvements.

Slater et al. (2019) highlighted some of the key R packages for hydrological modeling; TUWmodel is an R version of the HBV model originally written in Fortran (Viglione and Parajka, 2016); topmodel and dynatopmodel are the $\mathrm{R}$ versions of the well-known semi-distributed models TOPMODEL and Dynamic TOPMODEL (Buytaert, 2018; Metcalfe et al., 2015); airGR (Coron et al., 2017, 2020) includes several conceptual rainfall-runoff models, a snow accumulation and melt model and the associated functions for their calibration and evaluation; finally, hydromad (Andrews et al., 2011) provides a modeling framework for environmental hydrology through water balance accounting and flow routing in spatially aggregated catchments.

Of the models mentioned above, only airGR, hydromad, and TUWmodel present a snow routine to account for accumulation and melting processes (temperature index model), but none of them have routines to account for glacier mass balance. On the other hand, the glacierSMBM package (Groos and Mayer, 2017) allows the modeling of glacier surface mass balance in a fully distributed manner, but it was designed to work on the mass balance of a single glacier and to run on a raster-based grid, two aspects that limit its applicability at the basin scale.

The HBV.IANIGLA (Toum, 2021) package was built with the aim of providing a modular hydrological model approach that adds to the classic HBV routines functions for the modeling of the surface mass balance of clean and debris-covered glaciers, a fundamental aspect in the hydrological cycle of cold regions of the Andes (Masiokas et al., 2020). The main objective of this article is to present the HBV.IANIGLA model structure through its implementation as an R package to serve as a practical guide to better understand how it works. The paper is organized as follows:

- In the next section, we describe the modeling philosophy under HBV and justify the use of a modular approach. We then present the HBV.IANIGLA modules and related equations (with some conceptual drawings). We end this section with a small study on model computation times, a fundamental aspect for sensitivity and uncertainty analysis.

- Following the methodology, we focus on two examples: on a synthetic basin and on glacier mass balance. The reader will find more reproducible examples in the package vignettes. 
- Finally, we condense the key points of the current version of HBV.IANIGLA and propose future improvements.

\section{The HBV.IANIGLA model}

\section{The HBV model}

The HBV model has been used for 40 years for hydrological studies in mountain regions around the world (Bergström and Lindström, 2015). The model requires relatively few data inputs (air temperature, precipitation, and potential evapotranspiration), which makes it very appropriate in scarce data regions such as the Southern Andes. It has been well-documented by other authors (Seibert and Vis, 2012; Parajka and Blöschl, 2008; Stahl et al., 2008), a feature that facilitates writing new codes and modifying or improving existing equations. Also, it is a bucket-type model with relatively few free parameters to calibrate.

The HBV.IANIGLA version not only takes into account precipitation phase partitioning, snow accumulation and melting, actual evaporation and streamflow discharge, but also incorporates a module for simulating the surface mass balance of clean and debris-covered glaciers and another module for glacier-melt routing. In addition, the package has been designed in a modular fashion, allowing users to build their own model. To our knowledge, this is the first HBV version and $\mathrm{R}$ hydro-modeling package to combine these two features.

\section{General modeling philosophy}

According to Bergström and Lindström (2015), the HBV model was inspired in the works developed in the early 1970s by Nash and Sutcliffe (1970), O'Connell et al. (1970), and Mandeville et al. (1970). The primary objective of this model was operational: to forecast streamflow discharge for the Swedish hydropower industry. This overriding requirement dictated the characteristics of the model: it should not be too complex but physically sound; the input data should conform to standard Swedish meteorological measurements; the number of free parameters should be kept to a minimum; and it should be easy to understand.

The above features and lessons learned over more than two decades (Bergström, 1991) resulted in a hydrological model composed of four modules: (1) a temperature index model with an air temperature-based precipitation partitioning algorithm; (2) a soil moisture routine with a nonlinear empirical algorithm to account for abstractions, actual evaporation, and antecedent conditions; (3) a bucket-type model (many variants exist up to now) to simulate the catchment storage effect; and (4) a transfer function to adjust the timing of the hydrograph to the observed discharge.

To date, the model has not only been used in operational hydrology but also in scientific research. Konz and Seibert (2010) used the HBV-Light version in three alpine catchments in Switzerland and Austria to show the value of glacier mass balances in constraining uncertainty in the parameter estimation of conceptual models such as HBV. Ali et al. (2018) also applied HBV-Light to evaluate model performance in a climate change context in the snow- and ice-dominated Hunza River basin in the Karakoram Mountains, Pakistan. Finger et al. (2015) compared model performance in simulations of increasing complexity for glacier mass balance and streamflow at the outflow of three Swiss watersheds. Stahl et al. (2008) used HBV-CE to estimate streamflow sensitivity to different climate change scenarios in British Columbia, Canada. Staudinger et al. (2017) studied the variation of water storage with elevation in 21 Swiss alpine and pre-alpine catchments using four different methods: water balance analysis, flow recession analysis, calibration of the HBV model, and calibration of a transfer function hydrograph separation model using stable isotope observations. In another interesting application, Ren et al. (2018) combined HBV with a Bayesian neural network to improve seasonal water supply forecasting in the Yarkant River basin, Central Asia. Therefore, the original conception of HBV and its evolution have made it a longstanding multipurpose tool for a diverse and dynamic user community.

\section{Modules and equations}

Models are based on a perceptual conception of the basin's functioning. This perception leads to the decision of the equations (hydrological processes) and the construction of a conceptual model (Beven, 2012). In the HBV.IANIGLA model, these first two stages have already been decided, as the equations and coding are in the package, but the user still has a choice on how the watershed or glacier will be discretized (in terms of land use and spatial aggregation) and on how the different modules will be assembled. This decision should be guided by the objective of the project, the knowledge of the 
hydrological driving process at the chosen modeling scale, and the data available not only for the implementation but also for the model evaluation.

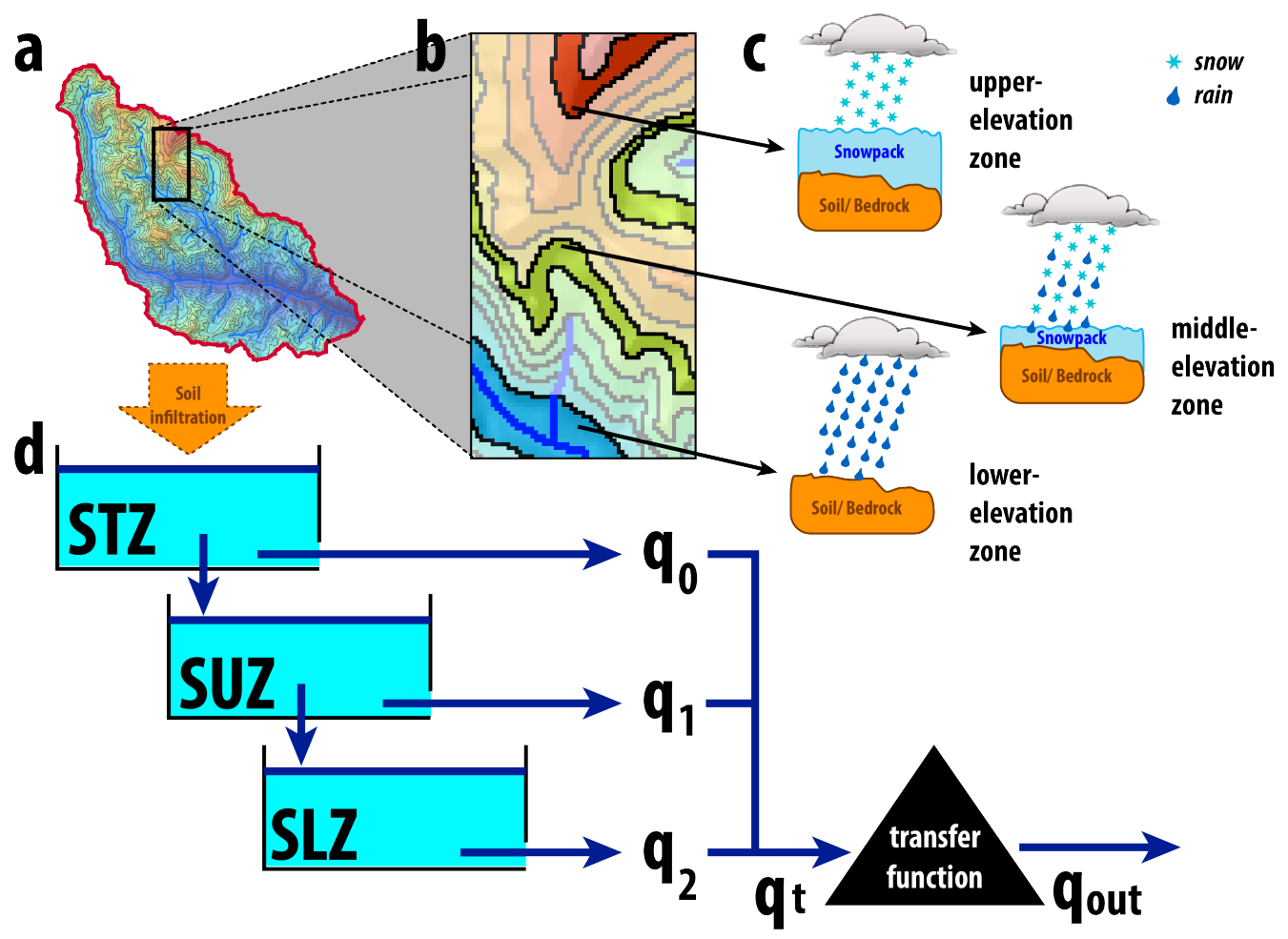

Figure 1: Example of HBV.IANIGLA module assembly in a mountain basin. To account for snow accumulation and snowmelt, the basin has been discretized into elevation bands ( $\mathbf{a}$ and $\mathbf{b})$. Each of these polygons has snow and soil routine (c), the effective soil recharge, weighted according to the relative area of the elevation band, is passed to the bucket model (d). Finally, the river runoff timing is adjusted by a triangular transfer function.

The following lines describe the modules that must be assembled to build a complete HBV.IANIGLA hydrological model. There are three other functions within the package: PET, Pecip_model, and Temp_ model. The first function contains a potential evapotranspiration model that provides a simple and straightforward way to calculate one of the inputs to the soil routine. However, for real-world applications we strongly recommend the use of the specialized Evapotranspiration package (Guo et al., 2020). The other two functions are linear models to extrapolate air temperature and precipitation records. Since we consider that their use is straightforward, we refer the user to the package manual.

\section{Snow and ice melt models - SnowGlacier_HBV()}

Precipitation is considered to be either snow or rain, depending on whether the temperature is above or below a threshold temperature $\operatorname{Tr}\left({ }^{\circ} \mathrm{C}\right)$.

$$
\begin{aligned}
& P_{\text {rain }}=P \quad \text { if } T_{\text {air }}>T r \\
& P_{\text {snow }}=P * S F C F \quad \text { if } \quad T_{\text {air }} \leq T r
\end{aligned}
$$

After partitioning, the snowfall is corrected using the SFCF parameter to account for the under-capture effect of the precipitation gauge on snow events.

This function uses a temperature index approach for snow and glacier melt simulation. This kind of approximation has been widely used in snow hydrology and glaciology, and different formulations have emerged (Hock, 2003; Seibert and Vis, 2012; Braun and Renner, 1992). The temperature index formulation takes into account the strong correlation between snow line retreat and accumulated temperatures above a certain threshold (with typical values around $0^{\circ} \mathrm{C}$ ). Hence although many authors have proposed more complex formulations (e.g., HBV-Light uses a refreezing and liquid retention factor) or even a radiation term (Pellicciotti et al., 2005), this empirical formulation must be parsimonious to avoid problems of overparameterization (Kirchner, 2006). 


$$
\text { Melt }=\left(T_{\text {air }}-T t\right) * f_{x} \quad \text { if } \quad T_{\text {air }}>T t,
$$

where $T_{\text {air }}$ is the measured or estimated air temperature, $T t$ is the melting temperature, and $f_{x}$ is a generic expression of melting factors for snow, clean, or debris-covered ice.

If the air temperature is above the threshold $(T t)$, melting occurs at a rate proportional to the melting factor $\left(f_{x}\right)$. Both the temperature threshold and the melting factor are parameters that must be calibrated by the user. Note that the time units depend on the resolution of the input data. Although the examples shown in this article are in a daily time step, the model can be used in the hourly or monthly resolution. In the next lines, we will describe in detail the different arguments of the function.

The model argument presents three options:

1. Temperature index model: this model is described by equation 2 . Here, the user can apply the most common and recommended set of temperature index formulations.

2. Temperature index model with variable snow cover area: this option is an attempt to offer, within the package, the same temperature index model as in the Snowmelt Runoff Model (DeWalle and Rango, 2008). However, this routine has certain limitation: the snow cover series forces the model to simulate a total effective value (e.g., snow water equivalent), which is not in-line with the original idea of modeling in elevation bands, where average values are expected.

3. Temperature index model with a variable glacier area: this routine explicitly takes into account the change in glacier area. Since the automatic reduction of glacier area forces the simulation to the observed values, the user should evaluate the correspondence between the simulated and observed mass balances.

The package documentation contains all the necessary information (vignettes with reproducible examples included) to correctly construct the inputData argument. The data matrix must not contain missing values (NA's) because HBV.IANIGLA is a continuous hydrological model, meaning that it simulates all the variables in every time step.

The initial conditions of the model are (initCond):

1. Initial snow water equivalent: this is a state variable, whose initial value will be used in the first loop. Unless field data is available, it is recommended to use a zero value. Because uncertainties are common in the initial state variables of the model, it is recommended to use a warm-up period (between one and two years in daily time step modeling). If the period covered by the data is very limited, these same values can be used as calibration parameters.

2. Numeric integer indicating the surface type: 1: clean ice; 2: soil; 3: debris-covered ice. HBV.IANIGLA uses this argument to know which parameters (param argument) to look for. It also constrains the function output.

3. Area of the glacier(s) (in the elevation band) relative to the basin: this is required only if the surface is a clean or debris-covered glacier. The area is used to scale the total amount of water produced (rainfall plus melted water) according to the area of the polygon in the basin. Thus, if the area of this portion of the glacier corresponds to $5 \%$ of the basin area, a value of 0.05 should be assigned.

The last argument is a numeric vector that stores the parameter values (param) of the modules. For debris-covered glaciers, a dummy value for the clean glacier melting factor $\left(f_{i c}\right)$ must be supplied. This value will not be used internally but simplifies the calibration exercise when working in a basin with both types of glaciers.

It should be noted that this function allows the construction of a single and lumped simulation. In order to develop the model for the example shown in figure 1, it will be necessary to build the model by running the function once per every elevation band (see examples in vignette (package = "HBV. IANIGLA")).

\section{Soil routine - Soil_HBV()}

This routine is based on an empirical formulation that takes into account actual evapotranspiration, antecedent conditions, and effective soil infiltration. This relationship is described by the so-called beta function (Bergström and Lindström, 2015),

$$
\text { Inf }=(\text { Melt }+ \text { Rainfall }) *\left(\frac{S M}{F C}\right)^{\beta},
$$


where Inf is the soil box infiltration, $S M$ is the soil moisture state variable, and $\beta$ is a nonlinear parameter between the total amount of water entering the soil box, soil moisture storage, and runoff generation. This equation is not unique among bucket-type hydrological models. A similar formulation can be found in the VIC model (Liang et al., 1994). HBV.IANIGLA assumes that all evapotranspiration occurs from the soil box, so this function implicitly accounts for all abstractions:

$$
E_{a c t}=E_{p o t} * \min \left(\frac{S M}{F C * L P} ; 1.00\right)
$$

where $E_{a c t}$ is the actual evapotranspiration, $E_{\text {pot }}$ is the potential evapotranspiration, $F C$ is the soil box water capacity parameter, and $L P$ is a reduction factor.

This type of relationship between potential, actual evapotranspiration, and soil moisture content has been found by Zhang et al. (2003) in eastern Asia, suggesting that despite its empirical formulation, in some places, it could have some physical meaning. Finally, and similar to the snow and ice melt modules, this routine represents a single and lumped simulation.

\section{Routine module - Routing_HBV()}

After infiltration, the water follows several complex pathways to streams (McDonnell, 2003). A detailed description and modeling of these water pathways requires field data and measurements that are generally not available. An early engineering-based solution to this issue was to consider this multi-causal delay as a water storage effect at the catchment scale (Dooge, 1973). This practical modeling approach could be seen as series of linearly interconnected and interrelated reservoirs (Sivapalan and Blöschl, 2017).

The current HBV.IANIGLA (version 0.2.1) has five different bucket formulations, which are selected by changing the model argument number (figure 2). To solve the time step change in the bucket water storage, we used the explicit finite difference form of the mass balance equation over a discrete-time step (Beven, 2012). Although the general solution has been implemented for a single linear reservoir (figure 3), we provide solutions for the five-bucket models.

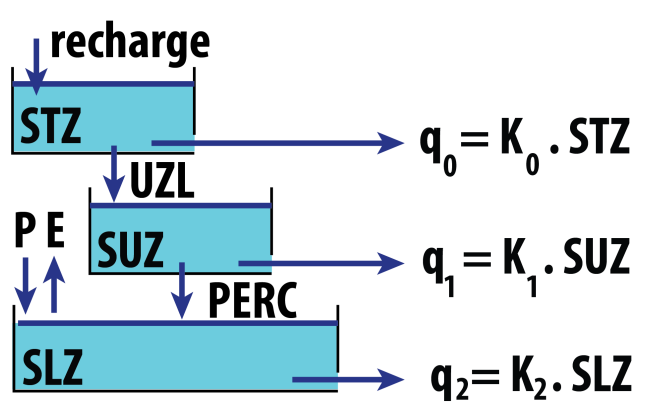

(a) Model 1

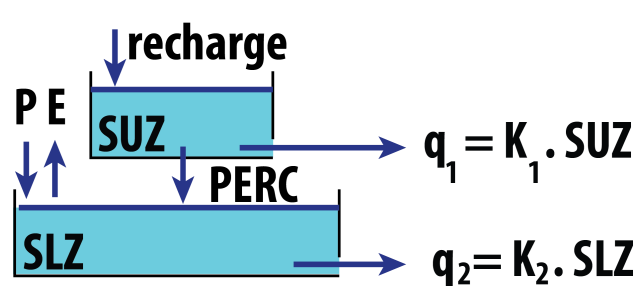

(b) Model 2

Figure 2: Diagrams for two of the five available bucket models. The reader will find all the diagrams in the help menu (?Routing_HBV).

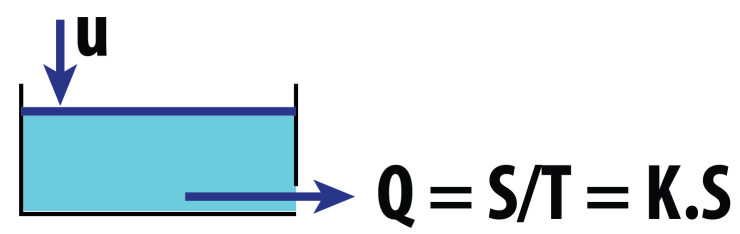

Figure 3: General outline for a water reservoir. 


$$
\begin{aligned}
& \frac{d S}{d t}=u-Q \quad \text { mass balance equation } \\
& Q=K * S \quad \text { continuity equation } \\
& \text { from (6), } \\
& S=\frac{Q}{K}=T * Q \\
& \text { we replace (7) into (5), } \\
& T * \frac{d Q}{d t}=u * Q
\end{aligned}
$$

In discrete time steps, we use the explicit finite difference form,

$$
\begin{aligned}
& \frac{Q_{t}-Q_{t-\Delta t}}{\Delta t}=\frac{u_{t}-Q_{t-\Delta t}}{T} \\
& Q_{t}=\frac{\Delta t}{T} * u_{t}+\left(1-\frac{\Delta t}{T}\right) * Q_{t-\Delta t} \\
& a=\left(1-\frac{\Delta t}{T}\right) \\
& b=\frac{\Delta t}{T} \\
& Q_{t}=a * Q_{t-\Delta t}+b * u_{t} \\
& \frac{S_{t}-S_{t-\Delta t}}{\Delta t}=u_{t}-Q_{t-\Delta t} \\
& S_{t}=S_{t-\Delta t}+\Delta t *\left(u_{t}-Q_{t-\Delta t}\right)
\end{aligned}
$$

\section{Glacier routine module - Glacier_Disch()}

Following an approach similar to previous routines, we adopt bucket storage and release scheme (Jansson et al., 2003). In HBV.IANIGLA, we use the approach proposed by Stahl et al. (2008) for the HBV-EC model, employed to estimate glacier and streamflow responses to future climate scenarios in the Bridge River Basin (British Columbia, Canada). The glacier outflow is calculated as:

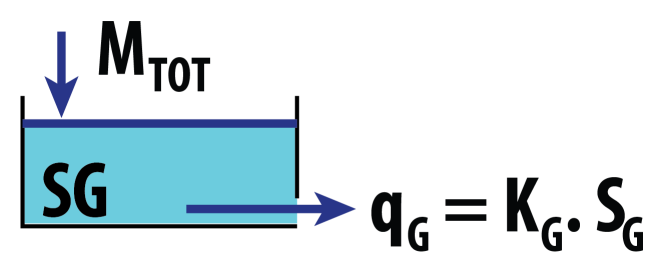

Figure 4: The glacier runoff release (precipitation plus snow and ice melt) is modeled as a linear water reservoir with a variable storage coefficient $\left(K_{G}\right)$, which is a function of the snow water equivalent above the ice body.

$$
\begin{aligned}
& K_{G}=K_{G \min }+d K_{G} * \exp (S W E / A G) \\
& q_{G}=K_{G} * S_{G},
\end{aligned}
$$

where $K_{G}$ is the actual glacier outflow coefficient, $K_{G \min }$ a minimum storage release coefficient, $d K_{G}$ the maximum glacier outflow increment, $S W E$ the total snow water equivalent over the glacier, $A G$ a scaling parameter, $S_{G}$ the glacier water storage, and $q_{G}$ the glacier runoff.

Note that the storage coefficient is a function of a minimum coefficient (denoting poor drainage conditions on the glacier), the snow water equivalent, and a calibration parameter. When the snowpack is at its maximum value, drainage occurs at a minimum rate, the opposite occurs in the late summer when all the snow on the glacier has melted.

For the resolution of the time step change, we also use the explicit finite difference formulation of the mass balance equation. 


\section{Transfer Function - UH()}

To represent the runoff routing in streams, we provide a single parameter triangular function. This parameter is calibrated to adjust the timing of the simulated river discharge,

$$
Q=\sum_{i=1}^{B_{\max }} Q_{t-i+1} * b_{i}
$$

where $B_{\max }$ is the base of the triangular weighting function, $b_{i}$ is the weight for the $i^{\text {th }}$ step, and $Q_{t-i+1}$ is the sum of the glacier and soil bucket runoff.

\section{Computation times}

The HBV.IANIGLA functions were written using Rcpp (Eddelbuettel, 2013; Eddelbuettel et al., 2019), a package that extends the $\mathrm{R}$ language using $\mathrm{C}++$. This approach combines the speed and efficiency of $\mathrm{C}++$, a compiled language, with the powerful interactive environment of $\mathrm{R}$ (see table 1), a language where it is easy to implement specific hydrological workflows (from data retrieval to results analysis) in a single environment (Slater et al., 2019).

\begin{tabular}{cccccc}
\hline min & lq & mean & median & uq & max \\
\hline 1.79 & 1.95 & 2.65 & 2.01 & 2.19 & 55.81 \\
\hline
\end{tabular}

Table 1: Summary of computation times (in milliseconds) over 1000 runs of the glacier_hbv function (see vignette("alerce_mass_balance")). The glacier was discretized into 8 elevation bands $(\sim 100$ $\mathrm{m}$ range). The model was built with the modules Temp_model, Precip_model, and SnowGlacier and was run on a daily time step over a period of almost 9 years (from 2010-01-01 to 2018-05-30). The analysis was performed on a CPU with an Intel Core i7-4790 processor at $3.60 \mathrm{GHz}$, on a 64 -bit OS running Ubuntu 18.04 using the microbechmark package (Mersmann, 2019).

Speed is an important issue for hydrological models, as it allows the user to perform not only uncertainty and sensitivity analysis in reasonable times, but also to apply demanding optimization algorithms such as DEoptim (Ardia et al., 2016) or different model structures. This is a recommended practice in the field of hydrological modeling (Beven, 2006, 2008; Pianosi et al., 2016). In addition, the package only depends on Rcpp (v 0.12.0), a fact that supports its long-term maintenance. If the reader is interested in comparing the computation times of different $\mathrm{R}$ hydrological models we recommend the work of Astagneau et al. (2020).

\section{Case studies}

\section{Lumped synthetic catchment}

As a first attempt at applying HBV.IANIGLA, a synthetic lumped catchment (the simplest hydrological model) is used to introduce the construction of the model and to present a basin discharge calibration exercise.

Initially, the dataset containing: date, air temperature, precipitation, potential evapotranspiration, and the catchment outflow is loaded, and then the model construction is conducted (from top to bottom).

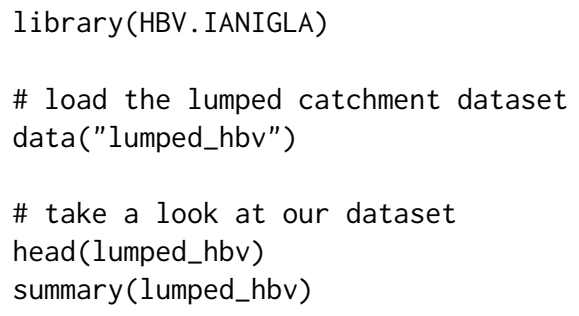

For a basin without glaciers, the SnowGlacier module is used only with soil as the underlying surface. In this exercise, we provide the correct initial conditions and parameters for all modules except the Routing_HBV function. Consistent with the development of hydrologic models, we build our 


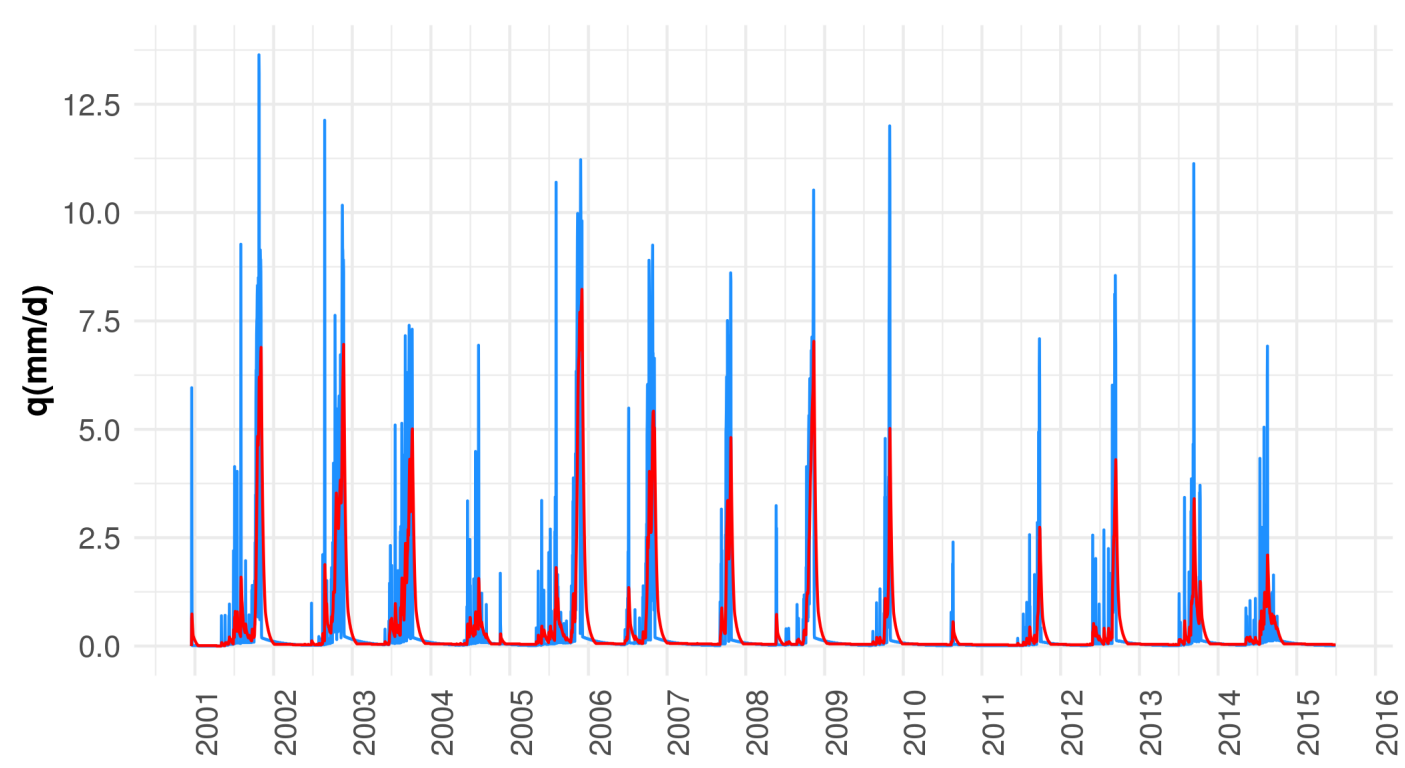

Figure 5: Observed (red) and simulated (blue) basin discharge. Note that the simulation does not precisely reproduce the observed basin discharge, suggesting that the model needs some calibration.

more information on this example, including the construction of an HBV model as a function and how to run a sensitivity analysis.

\section{Semi-distributed glacier mass balance}

In mountain areas with scarce meteorological information, temperature index models are widely used to simulate snow and ice melting (Hock, 2003; Konz and Seibert, 2010; Finger et al., 2015; Ayala et al., 2017). Since air temperature is the most readily available meteorological data in remote areas, the temperature index approach has been widely used in glaciological and hydrological modeling (Ohmura, 2001). This package has been built with the SnowGlacier_HBV function, a module that uses this empirical approach to simulate snow, clean ice, and debris-covered melting.

In this section, we simulate the glacier mass balance for the Alerce glacier. Located on Monte Tronador $\left(41.15^{\circ} \mathrm{S} ; 71.88^{\circ} \mathrm{W}\right)$, nearby the border between Argentina and Chile in the Andes of Northern Patagonia, Alerce is a medium-size mountain glacier with an area of about $2.33 \mathrm{~km}^{2}$ that ranges between 1629 and 2358 masl showing a SE aspect (Ruiz et al., 2017; IANIGLA-ING, 2018).

Since 2013, the Alerce glacier has been part of the monitoring network of the National Glacier Inventory (IANIGLA-ING, 2010). Measurements are conducted following the glaciological method for seasonal mass balance computation (Kaser et al., 2003). Puerto Montt precipitation (Dirección General de Aguas, Chile) and Bariloche air temperature (Servicio Meteorológico Nacional - Argentina) were used as meteorological records to simulate the annual mass balance of the glacier (data(alerce_data)). When calibrating the model parameters, simulations showing an annual mass balance in the range of $M B \pm 400 \mathrm{~mm}$ were considered acceptable. $M B$ is the annual surface mass balance of the glacier.

\#\# load the dataset

data(alerce_data)

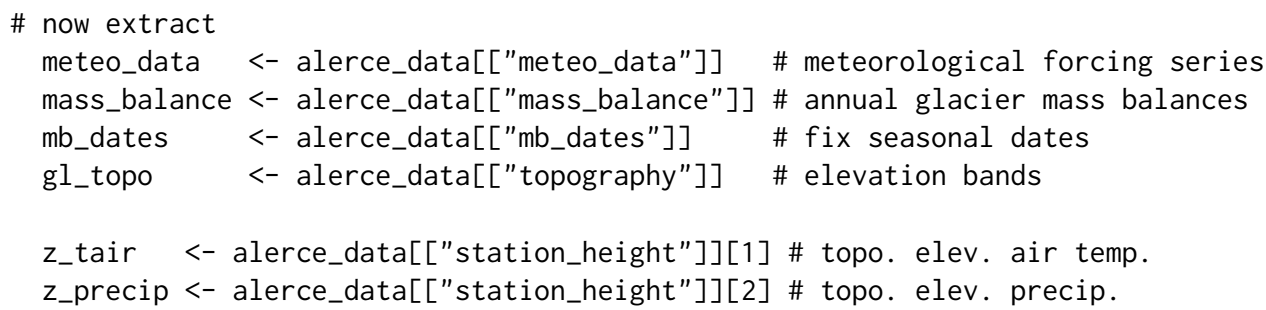

To evaluate the topographic effect on surface mass balance (derived from field measurements), the glacier was discretized into elevation bands. To solve this problem, a semi-distributed glacier surface mass balance model (glacier_hbv), an aggregation function (agg_mb - since measurements and 


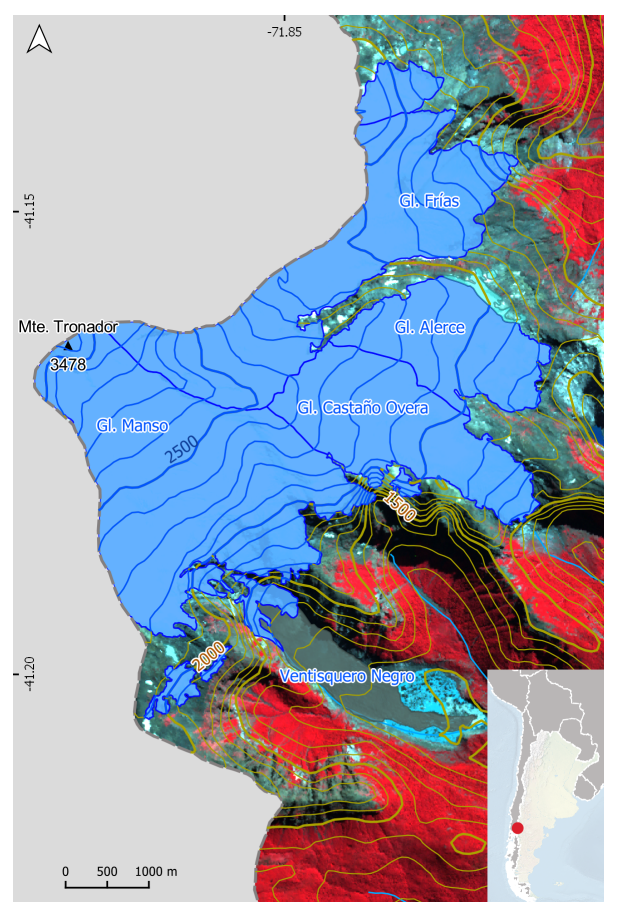

Figure 6: Satellite image of the Monte Tronador showing the location of the main glaciers. The Alerce glacier, located in the eastern sector, is one of the smallest glaciers at Monte Tronador.

simulations are on different temporal scales), and a goodness-of-fit function (my_gof) were constructed. The definition of this functions are included in vignette("alerce_mass_balance").

In the following code lines, the sampling strategy for finding acceptable parameter sets is indicated.

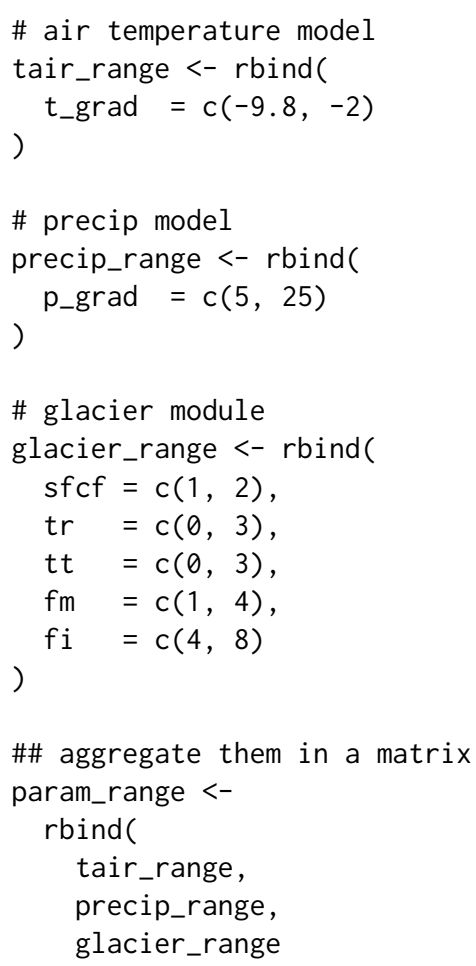

In the next step, we generate the random parameter sets:

\# set the number of model runs that you want to try

n_run $<-10000$

\# build the matrix 


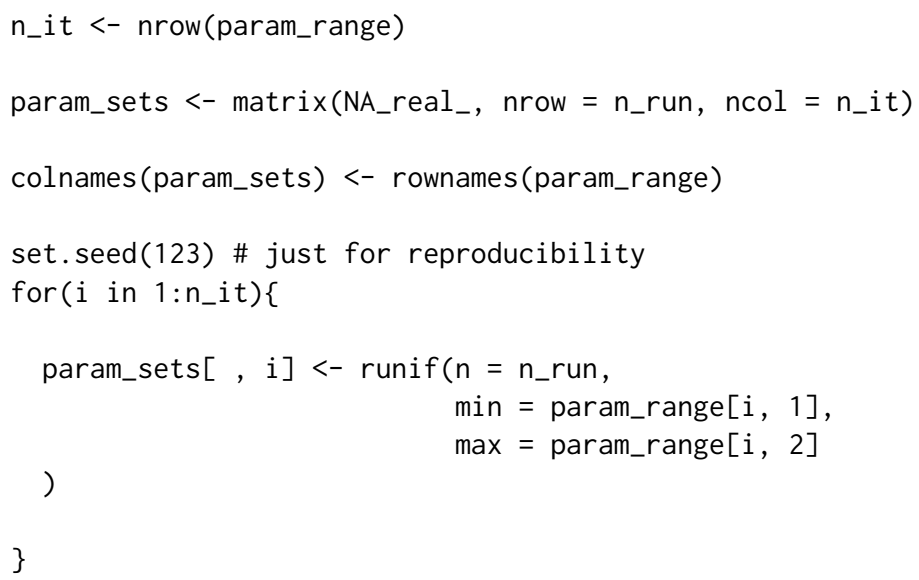

Now, we combine the functions and extract our best simulations.

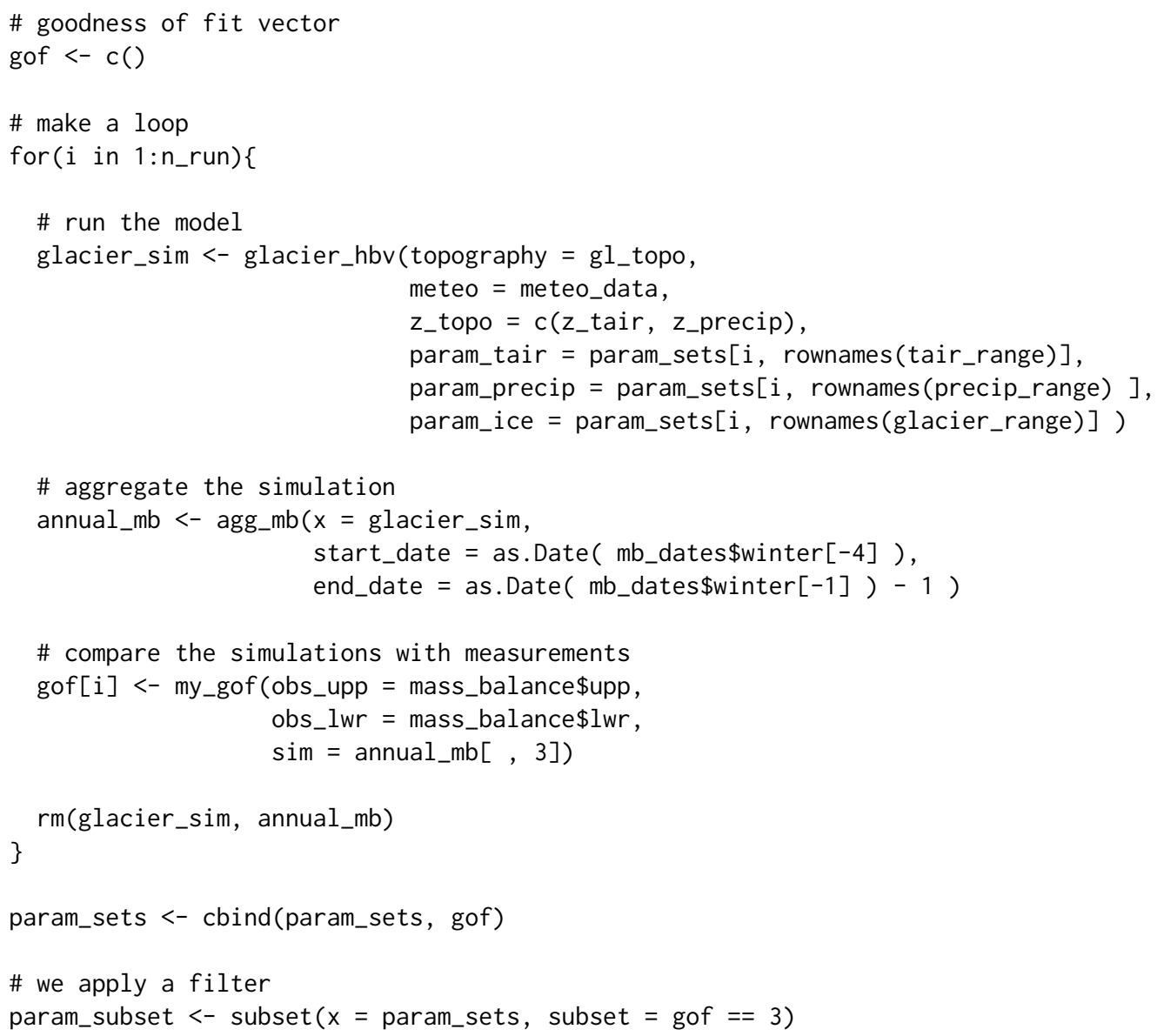

Once we have the subsetted our parameter matrix, we run the simulations to obtain a mean value (one per year).

\# now we run the model again to get our simulations

n_it $<-$ nrow(param_subset)

mb_sim <- matrix $\left(N_{-} \_r e a l_{-}\right.$, nrow $=3$, ncol $\left.=n_{-} i t\right)$

for (i in $\left.1: n_{-} i t\right)\{$

glacier_sim <- glacier_hbv(topography = gl_topo, meteo = meteo_data, $z_{-}$topo $=c\left(z_{-}\right.$tair, $z_{-}$precip $)$, param_tair $=$ param_subset $[i, \operatorname{rownames}($ tair_range $)]$, param_precip $=$ param_subset $[i, \operatorname{rownames}($ precip_range $)]$, param_ice $=$ param_subset $[i, \operatorname{rownames}($ glacier_range $)]$ ) 


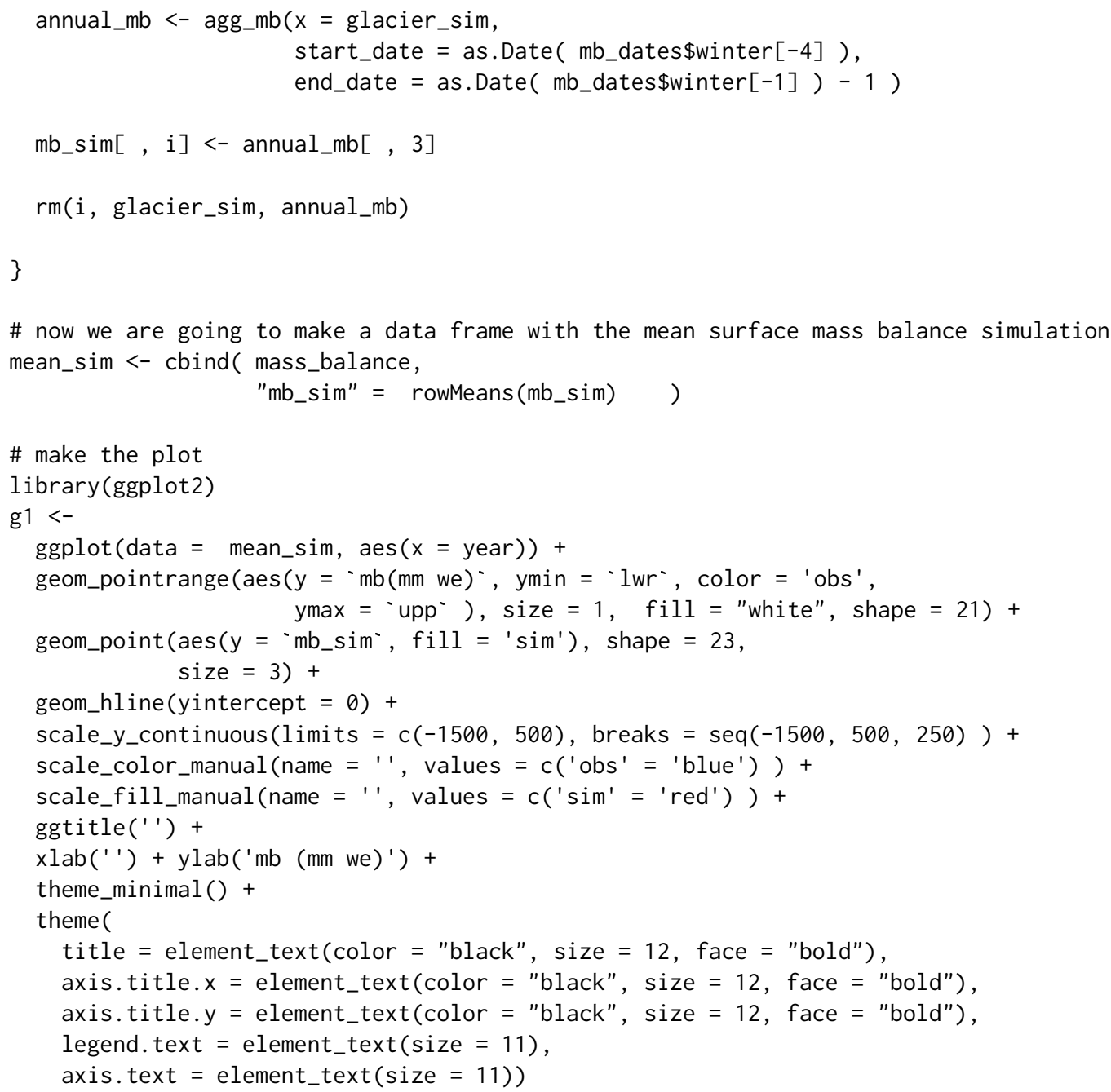

\section{Summary}

In this study, we present the HBV.IANIGLA package, a modular version of HBV hydrological model that incorporates routines for clean and debris-covered glacier modeling. We explain its modeling principles and philosophy; address the package modules and related equations; and reinforce the importance of $\mathrm{C}++$ code to speed up calculations, a characteristic that facilitates sensitivity and uncertainty analysis. To our knowledge, this is the first freely available, open-source modular version of the HBV model that incorporates routines for glacier surface mass balance modeling (clean and debris-covered ice).

We present two examples. The first one consists of a synthetic case to show how to build a model. This is the simplest hydrological modeling case and should be use to understand how to concatenate the package functions and how a numerical hydrological model works. The vignette("lumped_basin") also illustrates the importance of sensitivity analysis and shows how it can be easily done in R. In fact, any kind of sensitivity or uncertainty analysis (Pianosi et al., 2016) could be incorporated into HBV.IANIGLA. The second example, a real-world glacier surface mass balance estimation, was selected to show the use of the glacier module in a semi-distributed case. This module could be of interest to the glaciological community, extending the use of the R language to other scientific communities.

The new package version (0.2.1) documentation has been greatly improved in relation to previous versions, not only by clarifying some aspects of the existing function's documentation but also by adding six vignettes with reproducible examples (see vignette(package = "HBV.IANIGLA")).

The modular design of the package allows the use of various spatio-temporal scales with dissimilar objectives in the same environment (e.g., real-time streamflow forecasting, hydrological model teaching, or glacier mass balance simulation). The different modules can be combined with other 


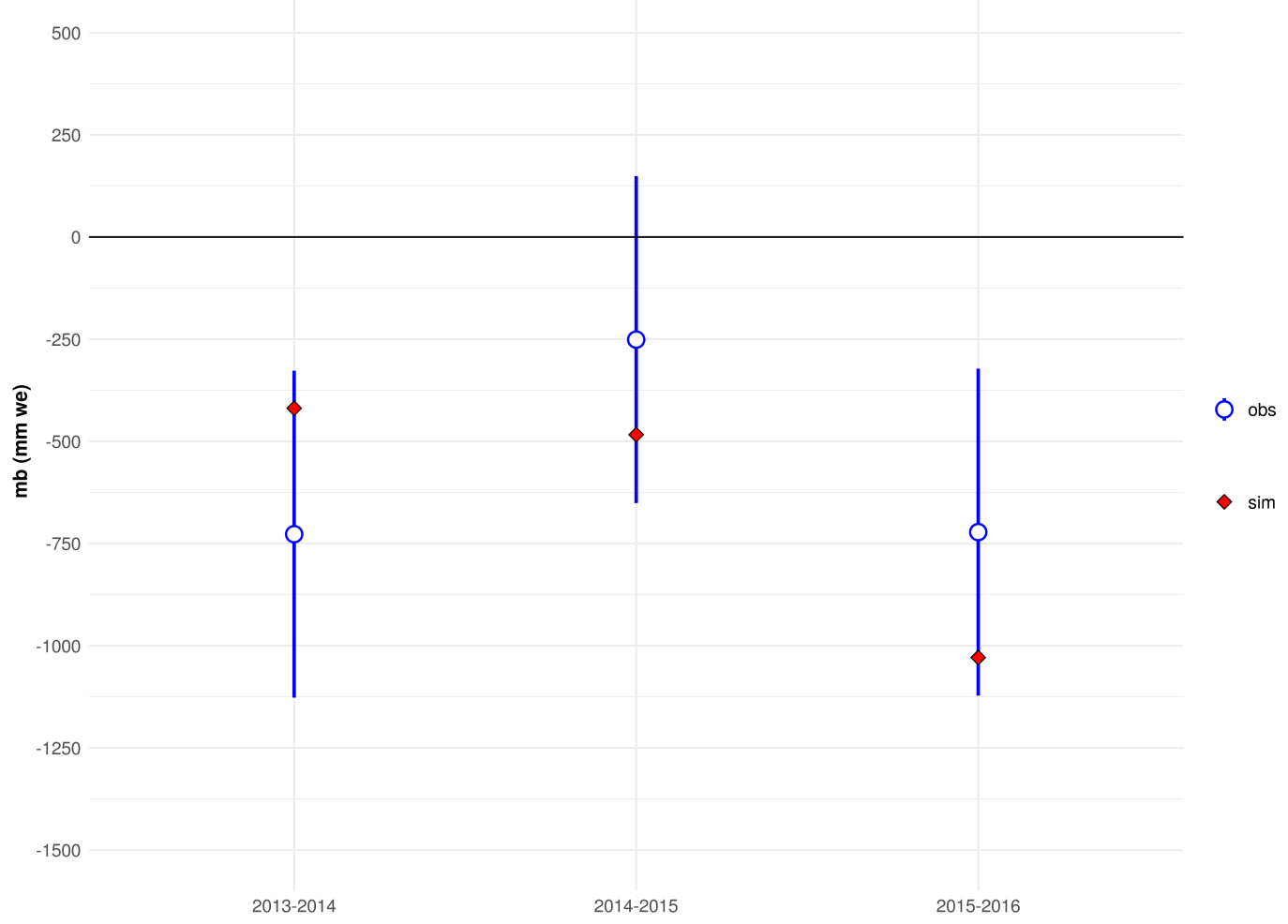

Figure 7: Annual mass balances for the period April 2013 - March 2016. All acceptable simulations lies between the observed uncertainty bounds (despite the fact that we have plot just the mean value).

R-related hydrological packages (e.g., Evapotranspiration, DEoptim, topmodel) or functions (Guo et al., 2019; Ardia et al., 2016; Buytaert, 2018).

HBV.IANIGLA can also be combined with packages such as tidyverse, sp, raster, hydroGOF, or plotly to build a single environmental hydrological workflow (Wickham, 2019; Pebesma and Bivand, 2017; Hijmans, 2017; Mauricio Zambrano-Bigiarini, 2017; Sievert et al., 2019). Thus, a hydrological project can be developed from the beginning to the end in the R environment, facilitating reproducible and repeatable research (Hutton et al., 2016; Ceola et al., 2015). This type of model design opens up the possibility for applications beyond the Andes region as well as to incorporate new functions, such as modules, to explicitly considering the dynamics of glaciers (Huss et al., 2010).

The package functions were built under generic classes (numeric vectors and matrices). This is an aspect where future improvements can be made. Since HBV.IANIGLA is available in modules, it could be greatly enhanced using the object-oriented programming (OOP) paradigm. In doing so, the model could represent an object with properties (e.g., areas, polygons, elevations, among others), and the HBV routines as part of the methods (functional OOP - S4 types). These methods may also include (but not limited to): sensitivity and uncertainty analysis, automatic plotting of results, and temporal aggregation functionality. Even some methods could be recycled from the hydroToolkit OOP package (Toum, 2020).

The package could also be improved by adding some GUI functionality keeping in mind that in the words of Chambers (2017), ...extending $R$ is about contributing to the language through applications designed for a wider audience than the package author itself. Moreover, this objective should not be a target by its own, but a part or a piece of a bigger project directed to solve real world problems.

\section{Acknowledgements}

E.T. acknowledges support from CONICET Argentina through a full-time PhD scholarship. The constructive suggestions from two anonymous reviewers were very useful for improving the article, the package documentation, and the vignettes, and are greatly appreciated. 


\section{Bibliography}

A. F. Ali, C.-d. Xiao, X.-p. Zhang, M. Adnan, M. Iqbal, and G. Khan. Projection of future streamflow of the Hunza River Basin, Karakoram Range (Pakistan) using HBV hydrological model. J. Mt. Sci., 15(10):2218-2235, Oct. 2018. ISSN 1993-0321. doi: 10.1007/s11629-018-4907-4. URL https: //doi.org/10.1007/s11629-018-4907-4. 0272. [p379]

F. T. Andrews, B. F. W. Croke, and A. J. Jakeman. An open software environment for hydrological model assessment and development. Environmental Modelling $\mathcal{E}$ Software, 26(10):1171-1185, Oct. 2011. ISSN 1364-8152. doi: 10.1016/j.envsoft.2011.04.006. URL http: //www. sciencedirect. com/ science/article/pii/S1364815211001046. [p378]

D. Ardia, K. Mullen, B. Peterson, and J. Ulrich. DEoptim: Global Optimization by Differential Evolution, 2016. URL https: //CRAN.R-project. org/package=DEoptim. R package version 2.2-4. [p384, 390]

P. C. Astagneau, G. Thirel, O. Delaigue, J. H. A. Guillaume, J. Parajka, C. C. Brauer, A. Viglione, W. Buytaert, and K. J. Beven. Hydrology modelling R packages: a unified analysis of models and practicalities from a user perspective. Hydrology and Earth System Sciences Discussions, pages 1-48, Oct. 2020. ISSN 1027-5606. doi: 10.5194/hess-2020-498. URL https://hess . copernicus . org/ preprints/hess-2020-498/. Publisher: Copernicus GmbH. [p384]

A. Ayala, F. Pellicciotti, N. Peleg, and P. Burlando. Melt and surface sublimation across a glacier in a dry environment: distributed energy-balance modelling of Juncal Norte Glacier, Chile. Journal of Glaciology, 63(241):803-822, Oct. 2017. ISSN 0022-1430, 1727-5652. doi: 10.1017/jog.2017.46. 0236. [p386]

S. Bergström. Principles and Confidence in Hydrological Modelling. Hydrology Research, 22(2):123-136, Apr. 1991. ISSN 0029-1277. doi: 10.2166/nh.1991.0009. URL https://doi .org/10. 2166/nh. 1991. 0009. [p379]

S. Bergström and G. Lindström. Interpretation of runoff processes in hydrological modelling-experience from the HBV approach. Hydrol. Process., 29(16):3535-3545, July 2015. ISSN 1099-1085. doi: 10.1002/hyp.10510. URL http://onlinelibrary.wiley.com/doi/10.1002/hyp. 10510/abstract. [p378, 379, 381]

K. Beven. A manifesto for the equifinality thesis. Journal of Hydrology, 320(1):18-36, Mar. 2006. ISSN 0022-1694. doi: 10.1016/j.jhydrol.2005.07.007. URL http://www. sciencedirect.com/science/ article/pii/s002216940500332X. 0126. [p384]

K. Beven. Environmental Modelling: An Uncertain Future? CRC Press, London, 1 edition edition, Sept. 2008. ISBN 978-0-415-45759-0. [p384]

K. J. Beven. Rainfall - Runoff Modelling. Wiley, Chichester, 2 edition edition, Mar. 2012. ISBN 978-0-47086671-9. [p379, 382]

L. N. Braun and C. B. Renner. Application of a conceptual runoff model in different physiographic regions of Switzerland. Hydrological Sciences Journal, 37(3):217-231, June 1992. ISSN 0262-6667. doi: 10.1080/02626669209492583. URL https://doi .org/10.1080/02626669209492583. [p378, 380]

W. Buytaert. topmodel: Implementation of the Hydrological Model TOPMODEL in R, 2018. URL https: //CRAN. R-project. org/package=topmodel. R package version 0.7.3. [p378, 390]

W. Buytaert, D. Reusser, S. Krause, and J.-P. Renaud. Why can't we do better than Topmodel? Hydrol. Process., 22(20):4175-4179, Sept. 2008. ISSN 1099-1085. doi: 10.1002/hyp.7125. URL http://onlinelibrary.wiley.com/doi/10.1002/hyp.7125/abstract. 0208. [p378]

S. Ceola, B. Arheimer, E. Baratti, G. Blöschl, R. Capell, A. Castellarin, J. Freer, D. Han, M. Hrachowitz, Y. Hundecha, C. Hutton, G. Lindström, A. Montanari, R. Nijzink, J. Parajka, E. Toth, A. Viglione, and T. Wagener. Virtual laboratories: new opportunities for collaborative water science. Hydrology and Earth System Sciences, 19(4):2101-2117, Apr. 2015. ISSN 1027-5606. doi: https://doi.org/ 10.5194/hess-19-2101-2015. URL https://www. hydrol-earth-syst-sci. net/19/2101/2015/hess19-2101-2015.html. [p390]

J. M. Chambers. Extending R. CRC Press, Dec. 2017. ISBN 978-1-4987-7572-4. Google-Books-ID: kxxjDAAAQBAJ. [p390]

L. Coron, G. Thirel, O. Delaigue, C. Perrin, and V. Andréassian. The suite of lumped GR hydrological models in an R package. Environmental Modelling and Software, 94:166-171, 2017. doi: 10.1016/j. envsoft.2017.05.002. [p378] 
L. Coron, O. Delaigue, G. Thirel, C. Perrin, and C. Michel. airGR: Suite of GR Hydrological Models for Precipitation-Runoff Modelling, 2020. URL https: //CRAN. R-project. org/package=airGR. R package version 1.4.3.65. [p378]

D. R. DeWalle and A. Rango. Principles of Snow Hydrology. Cambridge University Press, Cambridge, UK ; New York, July 2008. ISBN 978-0-521-82362-3. [p381]

J. Dooge. Linear Theory of Hydrologic Systems. Agricultural Research Service, U.S. Department of Agriculture, 1973. [p382]

D. Eddelbuettel. Seamless R and C++ Integration with Rcpp. Use R! Springer-Verlag, New York, 2013. ISBN 978-1-4614-6867-7. URL https://www. springer.com/gp/book/9781461468677. [p384]

D. Eddelbuettel, R. Francois, J. Allaire, K. Ushey, Q. Kou, N. Russell, D. Bates, and J. Chambers. Rcpp: Seamless $R$ and C++ Integration, 2019. URL https: //CRAN. R-project. org/package=Rcpp. R package version 1.0.2. [p384]

D. Finger, M. Vis, M. Huss, and J. Seibert. The value of multiple data set calibration versus model complexity for improving the performance of hydrological models in mountain catchments. Water Resour. Res., 51(4):1939-1958, Apr. 2015. ISSN 1944-7973. doi: 10.1002/2014WR015712. URL http://onlinelibrary.wiley.com/doi/10.1002/2014WR015712/abstract. [p379, 386]

A. R. Groos and C. Mayer. glacierSMBM: Glacier Surface Mass Balance Model, 2017. URL https: //CRAN. R-project.org/package=glacierSMBM. R package version 0.1. [p378]

D. Guo, S. Westra, and T. Peterson. Evapotranspiration: Modelling Actual, Potential and Reference Crop Evapotranspiration, 2019. URL https://CRAN. R-project.org/package=Evapotranspiration. $\mathrm{R}$ package version 1.14. [p390]

D. Guo, S. Westra, and T. Peterson. Evapotranspiration: Modelling Actual, Potential and Reference Crop Evapotranspiration, 2020. URL https://CRAN. R-project.org/package=Evapotranspiration. $\mathrm{R}$ package version 1.15. [p380]

R. J. Hijmans. raster: Geographic Data Analysis and Modeling, 2017. URL https: //CRAN. R-project.org/ package=raster. R package version 2.6-7. [p390]

R. Hock. Temperature index melt modelling in mountain areas. Journal of Hydrology, 282(1):104-115, Nov. 2003. ISSN 0022-1694. doi: 10.1016/S0022-1694(03)00257-9. URL http://www. sciencedirect. com/science/article/pii/s0022169403002579. [p380, 386]

M. Huss, G. Jouvet, D. Farinotti, and A. Bauder. Future high-mountain hydrology: a new parameterization of glacier retreat. Hydrol. Earth Syst. Sci., 14(5):815-829, May 2010. ISSN 1607-7938. doi: 10.5194/hess-14-815-2010. URL https://www. hydrol-earth-syst-sci. net/14/815/2010/. 0019. [p390]

C. Hutton, T. Wagener, J. Freer, D. Han, C. Duffy, and B. Arheimer. Most computational hydrology is not reproducible, so is it really science? Water Resources Research, 52(10):7548-7555, 2016. ISSN 1944-7973. doi: 10.1002/2016WR019285. URL https://agupubs. onlinelibrary.wiley. com/doi/ abs/10.1002/2016WR019285. [p390]

IANIGLA-ING. Inventario Nacional de Glaciares y Ambiente Periglacial:Fundamentos y Cronograma de Ejecución. Technical report, CONICET, Mendoza, 2010. URL http://www . glaciaresargentinos. gob.ar/wp-content/uploads/legales/fundamentos_cronograma_ejecucion.pdf. [p386]

IANIGLA-ING. IANIGLA-Inventario Nacional de Glaciares. 2018. Informe de las subcuencas de los ríos Manso, Villegas y Foyel. Cuenca de los ríos Manso y Puelo. IANIGLA-CONICET, Ministerio de Ambiente y Desarrollo Sustentable de la Nación. Technical report, IANIGLA, 2018. URL http://www.glaciaresargentinos.gob.ar. [p386]

P. Jansson, R. Hock, and T. Schneider. The concept of glacier storage: a review. Journal of Hydrology, 282(1):116-129, Nov. 2003. ISSN 0022-1694. doi: 10.1016/S0022-1694(03)00258-0. URL http: //www.sciencedirect.com/science/article/pii/s0022169403002580. 0229. [p383]

G. Kaser, A. Fountain, and P. Jansson. A manual for monitoring the mass balance of mountain glaciers. Manual 59, UNESCO, Paris, 2003. URL http://ulis2. unesco.org/images/0012/001295/129593E. pdf. 0396. [p386] 
J. W. Kirchner. Getting the right answers for the right reasons: Linking measurements, analyses, and models to advance the science of hydrology. Water Resources Research, 42(3), Mar. 2006. ISSN 1944-7973. doi: 10.1029/2005WR004362. URL https://agupubs. onlinelibrary.wiley.com/doi/ abs/10.1029/2005WR004362. 0216. [p380]

M. Konz and J. Seibert. On the value of glacier mass balances for hydrological model calibration. Journal of Hydrology, 385(1):238-246, May 2010. ISSN 0022-1694. doi: 10.1016/j.jhydrol.2010.02.025. URL http://www. sciencedirect.com/science/article/pii/s0022169410000958. 0189. [p379,386]

V. Krysanova, A. Bronstert, and D.-I. Müller-Wohlfeil. Modelling river discharge for large drainage basins: from lumped to distributed approach. Hydrological Sciences Journal, 44(2):313-331, Apr. 1999. ISSN 0262-6667. doi: 10.1080/02626669909492224. URL https://doi.org/10.1080/ 02626669909492224. [p378]

X. Liang, D. P. Lettenmaier, E. F. Wood, and S. J. Burges. A simple hydrologically based model of land surface water and energy fluxes for general circulation models. Journal of Geophysical Research: Atmospheres, 99(D7):14415-14428, 1994. ISSN 2156-2202. doi: https://doi.org/10. 1029/94JD00483. URL https://agupubs. onlinelibrary.wiley.com/doi/abs/10.1029/94JD00483. _eprint: https://agupubs.onlinelibrary.wiley.com/doi/pdf/10.1029/94JD00483. [p382]

A. N. Mandeville, P. E. O'Connell, J. V. Sutcliffe, and J. E. Nash. River flow forecasting through conceptual models part III - The Ray catchment at Grendon Underwood. Journal of Hydrology, 11 (2):109-128, Aug. 1970. ISSN 0022-1694. doi: 10.1016/0022-1694(70)90098-3. URL http://www. sciencedirect.com/science/article/pii/0022169470900983. [p379]

M. H. Masiokas, A. Rabatel, A. Rivera, L. Ruiz, P. Pitte, J. L. Ceballos, G. Barcaza, A. Soruco, F. Bown, E. Berthier, I. Dussaillant, and S. MacDonell. A Review of the Current State and Recent Changes of the Andean Cryosphere. Frontiers in Earth Science, 8, 2020. ISSN 2296-6463. doi: 10.3389/ feart.2020. 00099. URL https://www. frontiersin.org/articles/10.3389/feart.2020.00099/full. 0424. [p378]

Mauricio Zambrano-Bigiarini. hydroGOF: Goodness-of-Fit Functions for Comparison of Simulated and Observed Hydrological Time Series, 2017. URL https: //CRAN. R-project. org/package=hydroGOF. R package version 0.3-10. [p390]

J. J. McDonnell. Where does water go when it rains? Moving beyond the variable source area concept of rainfall-runoff response. Hydrological Processes, 17(9):1869-1875, 2003. ISSN 1099-1085. doi: https://doi.org/10.1002/hyp.5132. URL https://onlinelibrary.wiley.com/doi/abs/10.1002/ hyp.5132._eprint: https://onlinelibrary.wiley.com/doi/pdf/10.1002/hyp.5132. [p382]

O. Mersmann. microbenchmark: Accurate Timing Functions, 2019. URL https: //CRAN. R-project. org/ package=microbenchmark. R package version 1.4-7. [p384]

P. Metcalfe, K. Beven, and J. Freer. Dynamic TOPMODEL: A new implementation in R and its sensitivity to time and space steps. Environmental Modelling $\mathcal{E}$ Software, 72:155-172, Oct. 2015. ISSN 1364-8152. doi: 10.1016/j.envsoft.2015.06.010. URL http://www. sciencedirect.com/science/article/pii/ S1364815215001735. 0306. [p378]

J. E. Nash and J. V. Sutcliffe. River flow forecasting through conceptual models part I - A discussion of principles. Journal of Hydrology, 10(3):282-290, Apr. 1970. ISSN 0022-1694. doi: 10.1016/00221694(70)90255-6. URL http://www. sciencedirect.com/science/article/pii/0022169470902556. 0004. [p379]

P. E. O'Connell, J. E. Nash, and J. P. Farrell. River flow forecasting through conceptual models part II The Brosna catchment at Ferbane. Journal of Hydrology, 10(4):317-329, June 1970. ISSN 0022-1694. doi: 10.1016/0022-1694(70)90221-0. URL http://www. sciencedirect. com/science/article/pii/ 0022169470902210. [p379]

A. Ohmura. Physical basis for the temperature-based melt-index method. Journal of Applied Meteorology, 40(4):753-761, Apr. 2001. ISSN 0894-8763. doi: 10.1175/1520-0450(2001)040<0753:PBFTTB>2.0.CO;2. URL https://doi .org/10.1175/1520-0450(2001)040<0753:PBFTTB>2.0.c0;2. [p386]

J. Parajka and G. Blöschl. The value of MODIS snow cover data in validating and calibrating conceptual hydrologic models. Journal of Hydrology, 358(3):240-258, Sept. 2008. ISSN 0022-1694. doi: 10.1016/j.jhydrol.2008.06.006. URL http://www. sciencedirect.com/science/article/pii/ s0022169408002862. 0199. [p379]

E. Pebesma and R. Bivand. sp: Classes and Methods for Spatial Data, 2017. URL https://CRAN. Rproject. org/package=sp. R package version 1.2-5. [p390] 
F. Pellicciotti, B. Brock, U. Strasser, P. Burlando, M. Funk, and J. Corripio. An enhanced temperatureindex glacier melt model including the shortwave radiation balance: development and testing for Haut Glacier d'Arolla, Switzerland. Journal of Glaciology, 51(175):573-587, 2005. ISSN 0022-1430, 1727-5652. doi: 10.3189/172756505781829124. Publisher: Cambridge University Press. [p380]

F. Pianosi, K. Beven, J. Freer, J. W. Hall, J. Rougier, D. B. Stephenson, and T. Wagener. Sensitivity analysis of environmental models: A systematic review with practical workflow. Environmental Modelling E Software, 79:214-232, May 2016. ISSN 1364-8152. doi: 10.1016/j.envsoft.2016.02.008. URL http://www. sciencedirect.com/science/article/pii/S1364815216300287. 0324. [p384, 389]

W. W. Ren, T. Yang, C. S. Huang, C. Y. Xu, and Q. X. Shao. Improving monthly streamflow prediction in alpine regions: integrating HBV model with Bayesian neural network. Stoch Environ Res Risk Assess, 32(12):3381-3396, Dec. 2018. ISSN 1436-3259. doi: 10.1007/s00477-018-1553-x. URL https: //doi.org/10.1007/s00477-018-1553-x. 0359. [p379]

L. Ruiz, E. Berthier, M. Viale, P. Pitte, and M. H. Masiokas. Recent geodetic mass balance of Monte Tronador glaciers, northern Patagonian Andes. The Cryosphere, 11(1):619-634, Feb. 2017. ISSN 1994-0424. doi: 10.5194/tc-11-619-2017. URL https://www. the-cryosphere. net/11/619/2017/. 0237. [p386]

J. Seibert and M. J. P. Vis. Teaching hydrological modeling with a user-friendly catchment-runoffmodel software package. Hydrol. Earth Syst. Sci., 16(9):3315-3325, Sept. 2012. ISSN 1607-7938. doi: 10.5194/hess-16-3315-2012. URL https: //www. hydrol-earth-syst-sci . net/16/3315/2012/. 0021. $[\mathrm{p} 378,379,380]$

C. Sievert, C. Parmer, T. Hocking, S. Chamberlain, K. Ram, M. Corvellec, and P. Despouy. plotly: Create Interactive Web Graphics via 'plotly.js', 2019. URL https: //CRAN. R-project. org/package=plotly. R package version 4.9.0. [p390]

M. Sivapalan and G. Blöschl. The Growth of Hydrological Understanding: Technologies, Ideas, and Societal Needs Shape the Field. Water Resources Research, 53(10):8137-8146, 2017. ISSN 19447973. doi: 10.1002/2017WR021396. URL https://agupubs.onlinelibrary.wiley.com/doi/abs/ 10.1002/2017WR021396. 0413. [p382]

L. J. Slater, G. Thirel, S. Harrigan, O. Delaigue, A. Hurley, A. Khouakhi, I. Prodoscimi, C. Vitolo, and K. Smith. Using R in hydrology: a review of recent developments and future directions. Hydrology and Earth System Sciences Discussions, pages 1-33, Feb. 2019. ISSN 1027-5606. doi: https:/ /doi.org/ 10.5194/hess-2019-50. URL https: //www. hydrol-earth-syst-sci-discuss. net/hess-2019-50/. [p378, 384]

K. Stahl, R. D. Moore, J. M. Shea, D. Hutchinson, and A. J. Cannon. Coupled modelling of glacier and streamflow response to future climate scenarios. Water Resour. Res., 44(2):W02422, Feb. 2008. ISSN 1944-7973. doi: 10.1029/2007WR005956. URL http://onlinelibrary.wiley.com/doi/10.1029/ 2007WR005956/abstract. 0013. [p378, 379, 383]

M. Staudinger, M. Stoelzle, S. Seeger, J. Seibert, M. Weiler, and K. Stahl. Catchment water storage variation with elevation. Hydrological Processes, 31(11):2000-2015, 2017. ISSN 1099-1085. doi: 10.1002/hyp.11158. URL https://onlinelibrary.wiley.com/doi/abs/10.1002/hyp. 11158. [p379]

E. Toum. hydroToolkit: Hydrological Tools for Handling Hydro-Meteorological Data from Argentina and Chile, 2020. R package version 0.1.1. [p390]

E. Toum. HBV.IANIGLA: Modular Hydrological Model, 2021. URL https://CRAN. R-project.org/ package=HBV . IANIGLA. 0.2.0. [p378]

A. Viglione and J. Parajka. TUWmodel: Lumped Hydrological Model for Education Purposes, 2016. URL https://CRAN.R-project.org/package=TUWmodel. R package version 0.1-8. [p378]

H. Wickham. tidyverse: Easily Install and Load the 'Tidyverse', 2019. URL https: //CRAN. R-project. org/ package=tidyverse. $\mathrm{R}$ package version 1.3.0. [p390]

Y. Zhang, T. Ohata, K. Ersi, and Y. Tandong. Observation and estimation of evaporation from the ground surface of the cryosphere in eastern Asia. Hydrological Processes, 17(6):1135-1147, Apr. 2003. ISSN 1099-1085. doi: 10.1002/hyp.1183. URL http://onlinelibrary.wiley.com/doi/10.1002/ hyp. 1183/abstract. [p382] 
Ezequiel Toum

IANIGLA-CONICET

Av. Ruiz Leal s/n Parque General San Martin - Mendoza

Argentina

etoum@mendoza-conicet.gob.ar

Mariano H. Masiokas

IANIGLA-CONICET

Av. Ruiz Leal s/n Parque General San Martin - Mendoza Argentina

mmasiokas@mendoza-conicet.gob.ar

Ricardo Villalba

IANIGLA-CONICET

Av. Ruiz Leal s/n Parque General San Martin - Mendoza Argentina

ricardo@mendoza-conicet.gob.ar

Pierre Pitte

IANIGLA-CONICET

Av. Ruiz Leal s/n Parque General San Martin - Mendoza Argentina

pierrepitte@mendoza-conicet.gob.ar

Lucas Ruiz

IANIGLA-CONICET

Av. Ruiz Leal s/n Parque General San Martin - Mendoza Argentina

Iruiz@mendoza-conicet.gob.ar 